\title{
Blood pressure normalization by fixed perindopril/indapamide combination in hypertensive patients with or without associate metabolic syndrome: results of the OPTIMAX 2 study
}

\author{
Jean-Jacques Mourad' \\ Dulce Lameira' \\ Pierre-Jean Guillausseau ${ }^{2}$
}

'APHP, Service de Médecine interne, Hôpital Avicenne, Bobigny, France; ${ }^{2}$ APHP, Service de Médecine B, Hôpital Lariboisière, et Université Paris, Paris, France

Correspondance: Jean-Jacques Mourad Hôpital Avicenne, 125 rue de Stalingrad, 93009 Bobigny Cedex, France

$\mathrm{Tel}+33$ | 4895 5 | 4 |

Fax +33 I 48955668

Email jean-jacques.mourad@avc.aphp.fr

\begin{abstract}
The aim of the observational pharmaco-epidemiological study Optimax II was to seek whether the pre-existence of a metabolic syndrome (MS) defined by the NCEP-ATP III criteria impacts blood pressure (BP) control in hypertensive patients receiving a fixed perindopril/indapamide combination therapy. The primary objective of the study was to compare in patients with and without MS the rate of BP control defined as a systolic BP $\leq 140 \mathrm{mmHg}$ and a diastolic BP $\leq 90 \mathrm{mmHg}$. Patients were prospectively included and the follow-up lasted 6 months. The study population consisted of 24,069 hypertensive patients ( $56 \%$ men; mean age $62 \pm 11$ years; $18 \%$ diabetics; mean BP at inclusion $162 \pm 13 / 93 \pm 9 \mathrm{mmHg}$ ). MS was found in $30.4 \%$ of the patients $(n=7322): 35.2 \%$ women and $20.1 \%$ men. Three therapeutic subgroups were constituted: Group A, previously untreated, received the combination therapy as initial treatment; Group B, previously treated but with unsatisfactory results and/or treatment intolerance, had its previous treatment switched to perindopril/indapamide; and Group C, previously treated, with good treatment tolerance but uncontrolled BP, received the study treatment in adjunction to the previous one. The normalization rate was $70.3 \%$ in group A, $68.4 \%$ in Group $\mathrm{B}$, and $64.1 \%$ in Group C $(\mathrm{p}<0.0001)$. The pre-existence of MS did not show any significant influence on these rates since BP lowering was $-22.7 \pm 13.7$ (SBP) and $-12.0 \pm 10.0 \mathrm{mmHg}$ (DBP) in patients without MS and $-22.6 \pm 13.3$ (SBP) and $-12.1 \pm 9.7$ (DBP) in those with MS. The results of this study show a significant effect of perindopril/indapamide treatment on systolic BP lowering, whatever the treatment status: initiation, switch, or adjunctive therapy, and independently from the presence or not of MS. This effect may be related to the specific vascular effect of the perindopril/indapamide combination, which has recently demonstrated in the ADVANCE trial its ability to reduce mortality, and cardiovascular and renal complications in diabetic patients.
\end{abstract}

Keywords: hypertension, metabolic syndrome, combination therapy, antihypertensive efficacy

\section{Introduction}

The metabolic syndrome (MS) refers to a cluster of several features such as obesity, abnormal levels of blood lipids, pre-diabetes, and arterial hypertension, considered likely to induce a cardiovascular risk (Lakka et al 2002; Grundy et al 2004). Although known for about 20 years with the first pathogenic description by Reaven in the Banting lecture (Reaven 1988), the pathogenesis that underlies the clustering of diverse cardiovascular risk factors is beginning to be better understood. Indeed, recent studies demonstrate a strong 
link between initial microvascular damage, hypertension, and insulin resistance (De Jongh et al 2004). Primitive capillary rarefaction contributes to both increased blood pressure (BP) and impaired target organ perfusion. This decrease in blood flow leads to impaired glucose uptake in muscle, contributing to increased insulin resistance (Reaven 1988; Julius et al 1991).

Many definitions have been proposed to identify MS (Alberti and Zimmet 1998; Expert Panel 2001; Alberti et al 2005; Grundy et al 2005). None is clearly universal and the exact prevalence of MS in the general population has never been identified, with figures that change from one country to another (Ford et al 2002; Tonkin 2003; Hu 2004), depending on the definition used (Day 2007; Nilsson et al 2007; Qiao et al 2007; Rodilla et al 2007). Results may also differ depending on the analyzed population, with differences observed to be in relation with ethnicity (Ajjan et al 2007), gender (Mitrakou 2006; Royer et al 2007), or other factors such as body mass index (Choi et al 2007) or age (Kelishadi 2007). Nevertheless, among the various MS definitions, that of the National Cholesterol Education Program Adult Treatment Panel III (NCEP ATPIII) (Expert Panel 2001; Grundy et al 2005) seems to be somehow consensual. It defines MS as the existence of at least three out of the following five criteria: glucose intolerance, high triglycerides (TG), low HDL level, arterial pre-hypertension, and abdominal obesity.

Overall, the prevalence of this disorder that is currently observed to increase (Borch-Johnsen 2007) is a real concern in terms of public health (Balkau and Charles 1999; BorchJohnsen 2007). In France, MS prevalence in the general population has been estimated to reach $9 \%$ (Hu 2004). Several studies have analysed the prognostic value of MS (Lakka et al 2002), in particular among hypertensive populations (Schillaci et al 2004; Navarro et al 2007); they showed a significant increase in the occurrence of cardiovascular events in those patients with hypertension and MS, and a positive relationship between the incidence of cardiovascular events and the number of risk factors included in the MS (Schillaci et al 2004).

MS management is complex and multifocal; it combines non-pharmacologic measures and conventional pharmacologic treatment of the existent risk factors among which, due to the frequency of hypertension as one component of MS (Hu et al 2004), an antihypertensive therapy for BP normalization. Most recent international therapeutic guidelines recommend combination therapies using low doses of antihypertensive agents (ESC-ESH Guidelines 2007).

Whether the presence of MS has an impact on the therapeutic efficacy of an antihypertensive regimen has never been studied. The present pharmaco-epidemiologic observational study (OPTIMAX 2) has been conducted to identify potential relationships between the presence of MS in a population of hypertensive patients and the therapeutic results of an antihypertensive treatment implemented as recommended by the guidelines.

\section{Methods}

This observational study with a prospective inclusion of patients and 3-6 months of routine follow-up was carried out with the collaboration of either general practitioners, or community or hospital cardiologists. The investigators sample was randomly constituted, and stratified according to the geographic area of medical practice.

The primary objective of the study was to measure and compare the rate of BP normalization in hypertensive patients receiving a low-dose combined antihypertensive therapy (fixed-dose ACE inhibitor + diuretic (perindopril/indapamide)) according to the presence or absence of associate MS. Secondary objectives were the evaluation of the rate of BP normalization among the study population according to the number of identified risk factors, and the rate of BP normalization according to one of the following clinical conditions that necessitate combination therapy: A. Initiation of the fixed low-dose combination therapy in never-treated essential hypertensive patients (or patients having stopped their treatment for at least 3 months); B. Modification of an ongoing antihypertensive treatment by treatment switch to the study bitherapy in uncontrolled already treated patients or patients experiencing adverse effects with their medication; and C. Optimization of the antihypertensive treatment by adjunction of the study bitherapy in an uncontrolled, already treated patient.

Normalization was considered achieved when systolic $\mathrm{BP}$ was $\leq 140 \mathrm{mmHg}$ and diastolic $\mathrm{BP} \leq 90 \mathrm{mmHg}$; optimal normalization was achieved when systolic BP was $\leq 140$ $\mathrm{mmHg}$ and diastolic BP $\leq 90 \mathrm{mmHg}$, with no significant adverse side effects.

During the 2-month inclusion period, the investigators were asked to include the successive 6 patients who met the inclusion criteria, with, preferentially 2 adult ( $>18$ years) patients corresponding to each of the clinical situations described above. Inclusion criteria were those that justify the treatment in the therapeutic groups A, B, and C. Exclusion criteria were pregnancy in women, unavailability of the biological data necessary to ascertain the existence of MS, potential non-assiduity or impossibility to attend the followup visit, participation in another study. 
Data collection was carried out by a medical questionnaire completed by the investigator at the inclusion visit: age, gender, blood pressure (average of 2 BP measures separated by a 10-min interval), waist circumference, height, weight, biochemistry (TG, total cholesterol, HDL- and LDL-cholesterol, fasting glucose), ongoing metabolic and antihypertensive treatments, daily dosages, and the new antihypertensive therapy instituted according to the $\mathrm{A}, \mathrm{B}$, or $\mathrm{C}$ therapeutic situation. Then, 3-6 months after inclusion, another medical questionnaire was completed by the investigator to assess both efficacy and safety of the study treatment. Follow-up and treatment modalities were defined by the investigator.

MS was defined as the existence of at least three of the following criteria: fasting plasma glucose $\geq 6.1 \mathrm{mmol} / \mathrm{L}$; triglycerides level $>1.7 \mathrm{mmol} / \mathrm{L}$ and/or ongoing treatment; low HDL defined as a blood concentration $<1.04 \mathrm{mmol} / \mathrm{L}$ in men and $<1.30 \mathrm{mmol} / \mathrm{L}$ in women; arterial pre-hypertension defined by a systolic BP $>130 \mathrm{mmHg}$ and diastolic BP $>85 \mathrm{mmHg}$ and/or ongoing antihypertensive treatment; and abdominal obesity defined as a waist circumference $>102 \mathrm{~cm}$ in men and $>88 \mathrm{~cm}$ in women.

\section{Statistical analysis}

Descriptive statistics are provided for the whole included population and by subgroups of patients defined according to the clinical situation (A, B, C as described above). Qualitative variables are presented as the number of patients by analyzed modality, and the corresponding percentage. Quantitative variables are expressed by the number of subjects, means \pm standard deviation (SD), extreme values and, when necessary, median values and quartiles. In comparative analyses, the level of statistical significance was set at 5\%.

Normalization and optimal normalization rates were calculated and described overall and according to the following criteria: presence/absence of MS as defined by the NCEP-ATPIII; number of existent risk factors out of the five included in this definition; hypertension type at inclusion (systolic, diastolic, systolo-diastolic); tobacco consumption; history of peripheral arterial disease or type 1 or 2 diabetes; the therapeutic subgroup independently from the existence of associate MS; and identity of the antihypertensive therapy introduced at inclusion (ACE inhibitor/ diuretic agent or $\beta$-blocker/diuretic agent).

The prevalence of hypertension-related risk cofactors (target organ lesion such as left ventricular hypertrophy or renal failure; direct familial history of hypertension, cardiovascular disease or sudden cardiac death; and personal history of cardiovascular events such as stroke, myocardial infarction, angina, coronary revascularization, heart failure, peripheral artery disease, diabetes) was also calculated.

Between-group comparisons of the results were performed using $\mathrm{Chi}^{2}$ tests; in case such tests could not be performed, a Fisher's exact test was carried out.

Efficacy was analysed by comparison of BP values at inclusion and at the follow-up visit; in addition to overall efficacy, this parameter was analyzed also by therapeutic subgroup and according to the presence or not of MS. The comparison of BP evolution between the subgroups was carried out using a monofactorial (subgroup) ANOVA analysis; in case of significant difference, a $t$ test was performed.

In order to identify the factors that could be predictive of BP normalization, in the two subgroups of normalized and non-normalized patients, the following factors were described: gender, age, blood pressure at inclusion, target organ lesion, history of cardiovascular events, tobacco consumption, physical exercise, treatment prescribed at inclusion, and treatment tolerance. Then, the two subgroups were compared using a univariate logistic regression analysis; $10 \%$ was the level of significance to select a factor to be introduced in the multivariate analysis. The multivariate logistic regression analysis was carried out with the discriminating factors and the final model was elaborated by the stepwise method in the Logistic procedure of SAS ${ }^{\mathrm{TM}}$. The odds ratios of the most discriminating factors were calculated to determine the profile of normalized patients.

\section{Results \\ Clinical characteristics of the study population}

Of the 25,116 files obtained during the inclusion period, 24,591 were considered suitable for analysis; after elimination of the 522 files with protocol deviations or missing data, $24,069(97.9 \%)$ patients with hypertension and aged at least 18 years were confirmed protocol compliant and assessed. Their main clinical characteristics at inclusion are displayed in Table 1. A significant difference $(\mathrm{p}<0.0001)$ was observed for gender, with a slight majority of men (55.8\% vs $44.1 \%$; $\mathrm{p}<0.0001)$ in the total population, and for age, with patients younger in Group A (untreated) than in the two other groups. Except for these two parameters and a mild difference for BP level of untreated patients (slightly higher than in the two other groups), no significant difference on these clinical characteristics was observed between groups at inclusion.

About $30 \%$ of study patients presented with MS in addition to their hypertension. Table 2 displays the incidence of 
Table I Descriptive clinical characteristics of the patients at inclusion, displayed for all patients and by treatment group. Except for age and gender, no significant difference was observed between groups at inclusion

\begin{tabular}{|c|c|c|c|c|c|}
\hline & & $\begin{array}{l}\text { Group A } \\
n=8,138\end{array}$ & $\begin{array}{c}\text { Group B } \\
n=9,4 \text { I } 5\end{array}$ & $\begin{array}{l}\text { Group C } \\
n=6,516\end{array}$ & $\begin{array}{l}\text { All patients } \\
n=24,069\end{array}$ \\
\hline Gender* & $\%$ men & 58.0 & 52.9 & 57.1 & 55.8 \\
\hline Age* & Mean \pm SD & $58.2 \pm 11.4$ & $63.2 \pm 11.2$ & $64.4 \pm 10.6$ & $61.8 \pm 11.4$ \\
\hline Systolic BP (mmHg) & Mean \pm SD & $164.2 \pm 12.0$ & $159.1 \pm 13.2$ & $163.4 \pm 12.1$ & $162.0 \pm 12.7$ \\
\hline Diastolic BP (mmHg) & Mean \pm SD & $95.0 \pm 8.6$ & $91.7 \pm 9.1$ & $93.4 \pm 9.2$ & $93.3 \pm 9.1$ \\
\hline Triglycerides (mmol/L) & Mean \pm SD & $\mathrm{I} .45 \pm 0.7 \mathrm{I}$ & $1.46 \pm 0.69$ & $1.52 \pm 0.73$ & $\mathrm{I} .47 \pm 0.7 \mathrm{I}$ \\
\hline$>1.7 \mathrm{mmol} / \mathrm{L}$ & $\%$ & 23.3 & 23.7 & 27.2 & 24.5 \\
\hline Fasting glucose (mmol/L) & Mean \pm SD & $5.79 \pm 1.35$ & $5.91 \pm 1.48$ & $6.12 \pm 1.62$ & $5.93 \pm 1.49$ \\
\hline$\geq 6.1 \mathrm{mmol} / \mathrm{L}$ & $\%$ & 26.0 & 30.3 & 36.2 & 30.5 \\
\hline Total cholesterol $(\mathrm{mmol} / \mathrm{L})$ & Mean \pm SD & $5.82 \pm 1.01$ & $5.72 \pm 1.02$ & $5.71 \pm 1.06$ & $5.75 \pm 1.03$ \\
\hline HDL-cholesterol (mmol/L) & Mean \pm SD & $1.35 \pm 0.35$ & $\mathrm{I} .35 \pm 0.36$ & $1.32 \pm 0.35$ & $\mathrm{I} .34 \pm 0.36$ \\
\hline Men $<1.04 \mathrm{mmol} / \mathrm{L}$ & $\%$ & 18.7 & 19.3 & 22.7 & 20.0 \\
\hline Women $<1.30 \mathrm{mmol} / \mathrm{L}$ & $\%$ & 30.0 & 30.8 & 32.1 & 30.9 \\
\hline LDL-cholesterol (mmol/L) & Mean \pm SD & $3.63 \pm 0.90$ & $3.52 \pm 0.89$ & $3.52 \pm 0.91$ & 3.560 .90 \\
\hline Waist circumference $(\mathrm{cm})$ & Mean \pm SD & $97.7 \pm 13.6$ & $98.0 \pm 13.8$ & $99.7 \pm 14.1$ & $98.4 \pm 13.8$ \\
\hline Men $>102 \mathrm{~cm}$ & $\%$ & 44.8 & 45.7 & 51.1 & 46.9 \\
\hline Women $>88 \mathrm{~cm}$ & $\%$ & 59.5 & 62.4 & 65.0 & 62.2 \\
\hline Weight (kg) & Mean \pm SD & $80.1 \pm 15.0$ & $79.7 \pm 14.9$ & $81.8 \pm 15.4$ & $80.4 \pm 15.1$ \\
\hline Height $(\mathrm{cm})$ & Mean \pm SD & $169.0 \pm 8.4$ & $167.8 \pm 8.3$ & $168.3 \pm 8.4$ & $168.3 \pm 8.4$ \\
\hline Anti-diabetic therapy & $\%$ & 11.7 & 18.5 & 25.8 & 18.2 \\
\hline Lipid-lowering therapy & $\%$ & 28.8 & 42.4 & 53.7 & 40.8 \\
\hline
\end{tabular}

$*_{\mathrm{p}}<0.0001$

MS among the study population; no significant difference was observed between groups. The most frequent criterion associated with hypertension was abdominal obesity; although not reaching statistical significance, this criterion, like HDLcholesterol, was observed predominantly in women.

Several hypertension-related cofactors of cardiovascular risk were evident in the study population, as shown by Figure 1. In the three groups, elevated values were found for some cofactors of cardiovascular risk such as a poor practice of physical exercise (about $71 \%$ of the patients), a familial history of arterial hypertension (about 45\%), tobacco consumption (about 26\%), and type 2 diabetes (about 17\%). Statistical differences between groups were found on all parameters, with the highest values observed in Group C; age-adjusted and gender-adjusted analyses show also statistically significant differences between Group A and Group C ( $\mathrm{p}<0.0001)$ except for tobacco consumption. In the population distributed according to the presence or absence of MS, the prevalence of all hypertension-related cofactors of cardiovascular risk was significantly raised in the subgroup with MS compared with patients without, except for stroke (Table 3).

\section{Treatment effect}

Before inclusion in the study, in Group B (non-normalized treated patients with adverse effects necessitating treatment switch) the most frequent treatments were: calcium channel blockers (26.6\%), diuretics (27.7\%), ACE inhibitors (26.2\%) and $\beta$-blockers (20\%); 19\% were under bitherapy while $4.1 \%$ were receiving 3 agents and $1 \%$ more than 3 drugs. In Group C (non normalized treated patients without adverse effects, necessitating adjunctive antihypertensive treatment) the most frequent treatments were: calcium channel blockers $(48.9 \%)$, and $\beta$-blockers (44.6\%); $28.7 \%$ of the patients were under bitherapy while $9.5 \%$ were receiving 3 agents and $2.4 \%$ more than 3 drugs.

During the follow-up period, the normalization rate was $70.3 \%$ in Group A, $68.4 \%$ in Group B and $64.1 \%$ in Group C ( $<<0.0001)$. Optimal control (normalized BP and no adverse effect) was obtained in $69.8 \%$ of the Group A, $67.9 \%$ of the Group B, and $63.7 \%$ of the Group $\mathrm{C}(\mathrm{p}<0.0001)$.

In none of the three therapeutic groups did the presence of pre-existing MS have any influence on the normalization rate: $66.7 \%$ in patients with MS, and $68.4 \%$ in patients without $(\mathrm{p}=0.52)$; optimal normalization rate was $66.4 \%$ in patients with MS and $67.7 \%$ in those without. The absence of any influence of MS on the lowering of BP was observed, whatever the number of factors that constitute the syndrome. As shown in Figure 2, when the population was distributed according to the presence or not of MS and by treatment 
Table 2 Prevalence of metabolic syndrome among the study population as a whole and distributed by therapeutic group

\begin{tabular}{|c|c|c|c|c|}
\hline & $\begin{array}{l}\text { Group A } \\
n=8,138\end{array}$ & $\begin{array}{l}\text { Group B } \\
n=9,415\end{array}$ & $\begin{array}{l}\text { Group C } \\
n=6,5 \text { I } 6\end{array}$ & $\begin{array}{l}\text { All patients } \\
n=24,069\end{array}$ \\
\hline Prevalence of metabolic syndrome & $26.4 \%$ & $30.7 \%$ & $35.0 \%$ & $30.4 \%$ \\
\hline Fasting glucose $\geq 6.1 \mathrm{mmol} / \mathrm{L}$ & $26.0 \%$ & $30.3 \%$ & $36.2 \%$ & $30.5 \%$ \\
\hline Triglycerides $>1.7 \mathrm{mmol} / \mathrm{L}$ & $23.3 \%$ & $23.7 \%$ & $27.2 \%$ & $24.5 \%$ \\
\hline Hypertension ${ }^{\mathrm{a}}$ (raised BP or treatment) & $100.0 \%$ & $100.0 \%$ & $100.0 \%$ & $100.0 \%$ \\
\hline \multicolumn{5}{|l|}{ HDL-cholesterol } \\
\hline$<1.04 \mathrm{mmol} / \mathrm{L}$ in men & $18.7 \%$ & $19.3 \%$ & $22.7 \%$ & $20.0 \%$ \\
\hline$<1.30 \mathrm{mmol} / \mathrm{L}$ in women & $30.0 \%$ & $30.8 \%$ & $32.1 \%$ & $30.9 \%$ \\
\hline \multicolumn{5}{|l|}{ Waist circumference } \\
\hline$>102 \mathrm{~cm}$ in men & $44.8 \%$ & $45.7 \%$ & $51.1 \%$ & $46.9 \%$ \\
\hline$>88 \mathrm{~cm}$ in women & $59.5 \%$ & $62.4 \%$ & $65.0 \%$ & $62.2 \%$ \\
\hline \multicolumn{5}{|l|}{ Number of MS criteria } \\
\hline I criterion & $39.7 \%$ & $36.2 \%$ & $32.8 \%$ & $36.4 \%$ \\
\hline 2 criteria & $33.9 \%$ & $33.1 \%$ & $32.3 \%$ & $33.2 \%$ \\
\hline 3 criteria & $17.2 \%$ & $19.6 \%$ & $21.9 \%$ & $19.4 \%$ \\
\hline 4 criteria & $7.6 \%$ & $8.7 \%$ & $10.5 \%$ & $8.8 \%$ \\
\hline 5 criteria & $1.7 \%$ & $2.4 \%$ & $2.5 \%$ & $2.2 \%$ \\
\hline
\end{tabular}

aHypertension was a criterion for eligibility to the study. This is the reason why this parameter is quoted $100 \%$ in all groups.

$\square \operatorname{Group} A(N=8,138) \quad \square \operatorname{Group} B(N=9,415) \quad \square$ Group $C(N=6,516)$

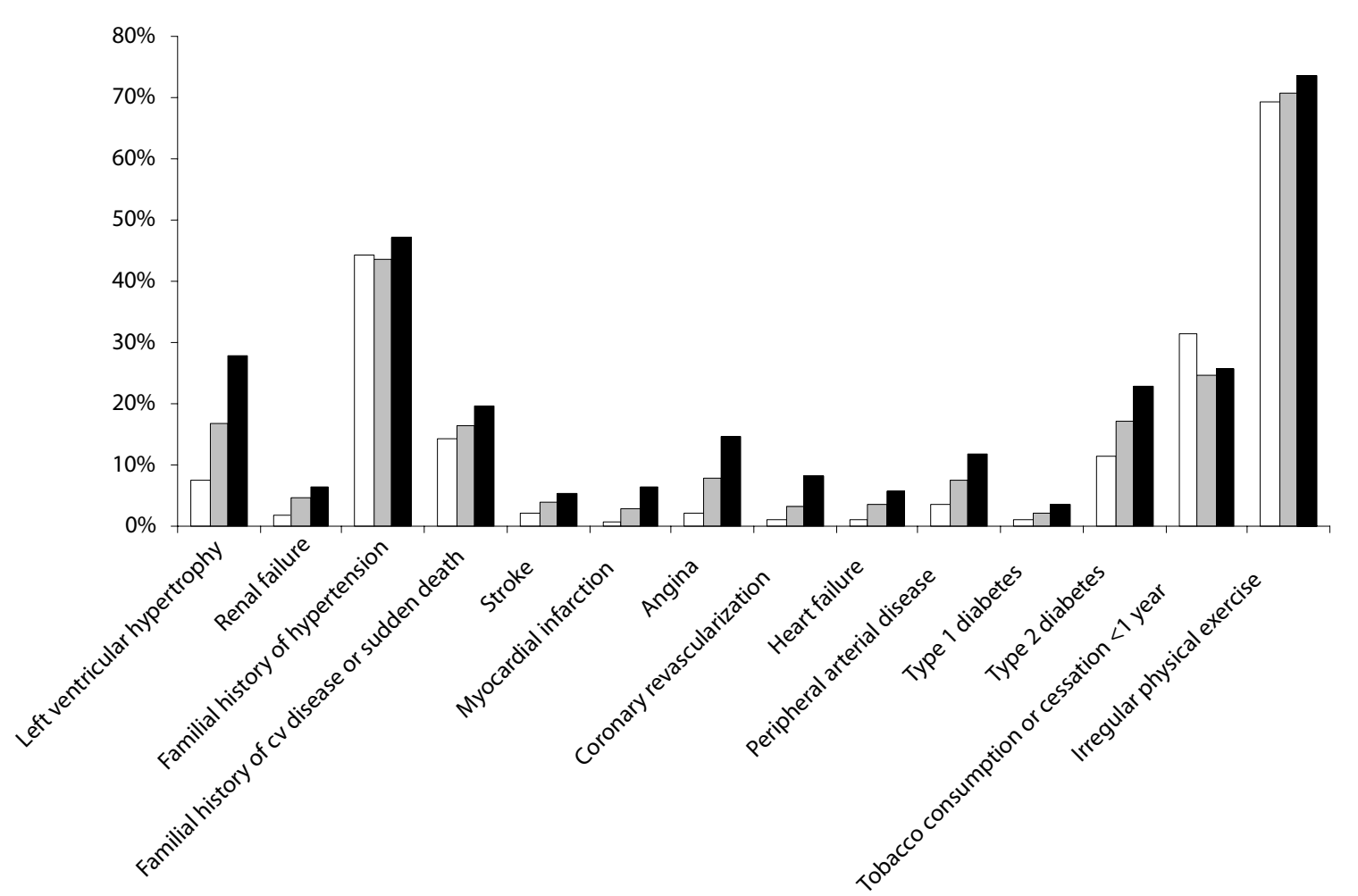

Figure I Incidence of hypertension-related cofactors of cardiovascular risk in the study population distributed by therapeutic group. For all parameters, significant differences $(p<0.0001)$ were found between groups except for the familial history of hypertension (ns between Group A and Group B), and tobacco consumption (ns between Group B and Group C). 
Table 3 Incidence of hypertension-related cofactors of cardiovascular risk in the study population distributed according to the presence or absence of MS. For all parameters except personal history of stroke (equivalent incidence), significant differences $(\mathrm{p}<0.00 \mathrm{I}$ ) were found between groups

\begin{tabular}{|c|c|c|c|}
\hline & Patients without MS $n=16,747$ & Patients with MS $n=7,322$ & p value \\
\hline \multicolumn{4}{|l|}{ Target organ lesion } \\
\hline Left ventricular hypertrophy & $14.4 \%$ & $21.5 \%$ & $<0.000$ I \\
\hline Renal failure & $3.8 \%$ & $4.9 \%$ & 0.0002 \\
\hline \multicolumn{4}{|l|}{ Direct familial history } \\
\hline Arterial hypertension & $42.8 \%$ & $49.3 \%$ & $<0.0001$ \\
\hline Cardiovascular disease or sudden death & $15.0 \%$ & $20.1 \%$ & $<0.0001$ \\
\hline \multicolumn{4}{|l|}{ Personal history of cardiovascular disease } \\
\hline Stroke & $3.7 \%$ & $3.6 \%$ & 0.66 \\
\hline Myocardial infarction & $2.8 \%$ & $3.9 \%$ & $<0.0001$ \\
\hline Angina & $6.4 \%$ & $10.6 \%$ & $<0.0001$ \\
\hline Coronary revascularization & $3.5 \%$ & $4.6 \%$ & $<0.000$ I \\
\hline Heart failure & $2.6 \%$ & $4.6 \%$ & $<0.000$ I \\
\hline Peripheral arterial disease & $6.5 \%$ & $9.5 \%$ & $<0.000$ I \\
\hline Type I diabetes & $1.4 \%$ & $4.0 \%$ & $<0.000$ I \\
\hline Type 2 diabetes & $10.1 \%$ & $32.2 \%$ & $<0.0001$ \\
\hline Tobacco consumption or cessation $<I$ year & $26.7 \%$ & $28.3 \%$ & 0.0092 \\
\hline Irregular physical exercise & $66.7 \%$ & $80.8 \%$ & $<0.0001$ \\
\hline
\end{tabular}

group, significant differences were found between the normalization rates of Group $\mathrm{A}, \mathrm{B}$, and $\mathrm{C}$ indicating an effect of the treatment independent from the pre-existence of MS.

In the total population, as in the three subgroups of patients, BP was significantly lowered after treatment
( $p<0.0001)$ (Figure 3). This BP control was especially marked for systolic BP which decreased significantly from baseline in the whole group of patients $(-22.7 \pm 13.5 \mathrm{mmHg})$ and in each of the three groups: $-25.5 \pm 12.9 \mathrm{mmHg}$ in Group $\mathrm{A},-19.9 \pm 13.7 \mathrm{mmHg}$ in Group B, and $-23.1 \pm 13.2 \mathrm{mmHg}$ in Group C ( $p<0.0001$ for all).

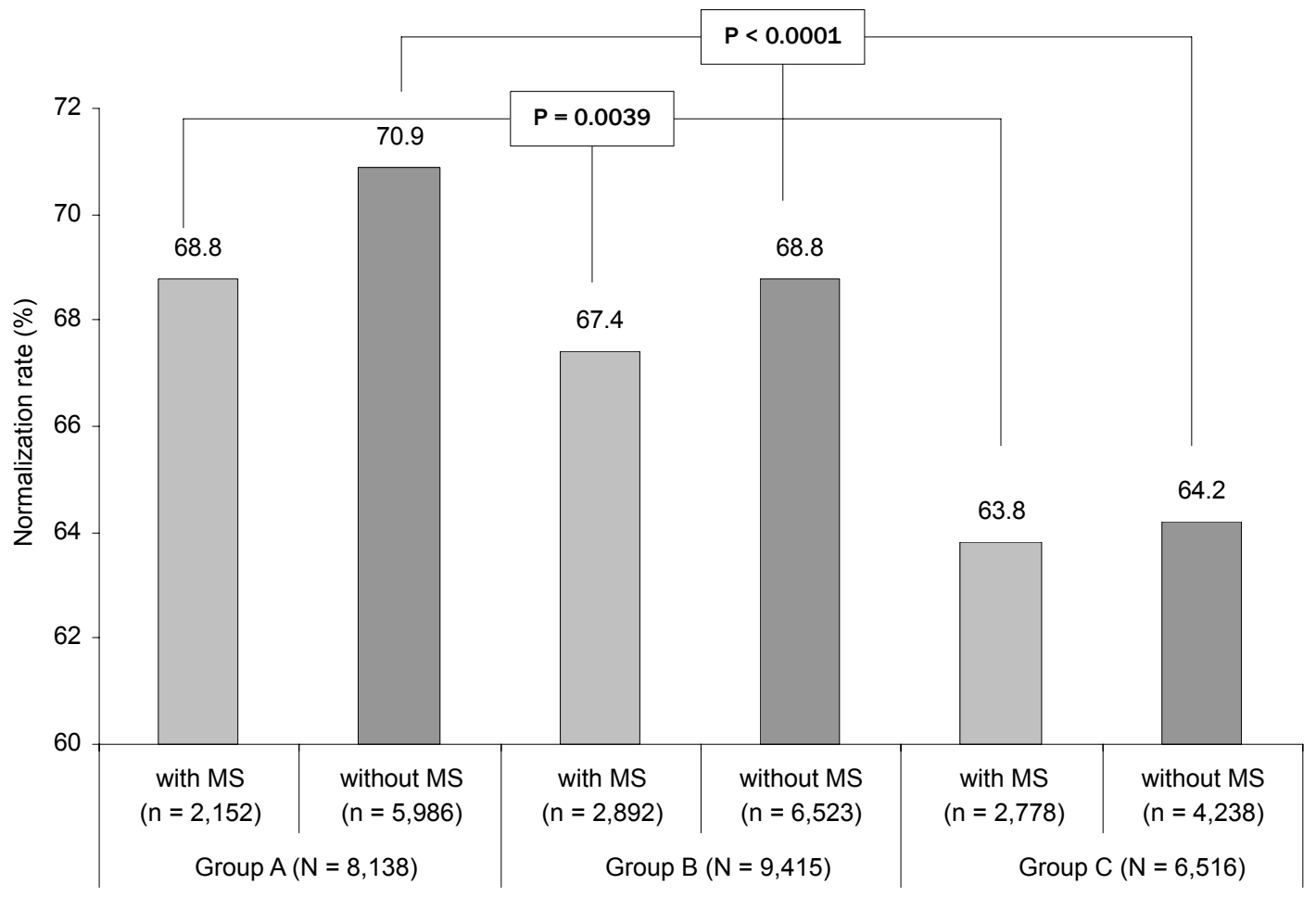

Figure 2 Rates of BP control among the study patients distributed by treatment group and according to the presence or not of MS. No significant difference was observed between the group of patients with MS vs the group of patients without MS ( $P=N S$ ), but significant differences were found between subgroups $A$, $B$, and $C$ among the two patient groups "with MS" and "without MS". 


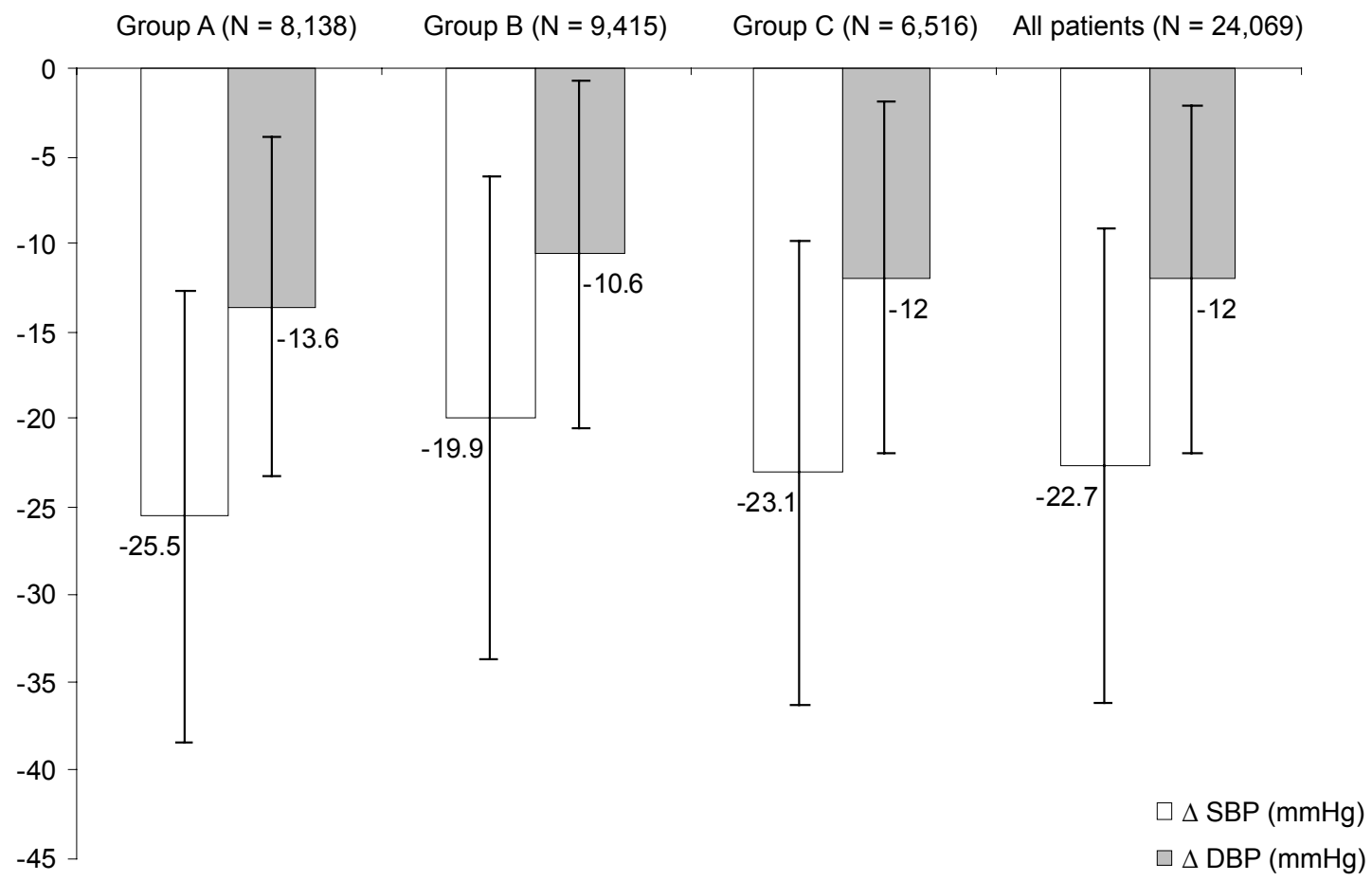

Figure 3 BP lowering (difference from baseline) in the population as a whole and in the three subgroups of patients. Significant differences were found both on the comparison between groups $(\mathrm{P}<0.000 \mathrm{I}$ for all) and on BP difference from baseline $(\mathrm{p}<0.000 \mathrm{I})$.

\section{Predictive factors of BP control}

After the stepwise procedure, the factors selected as relevant for the elaboration of the logistic regression model were the gender, age class, SBP and DBP at inclusion, presence of left ventricular hypertrophy, diabetes and renal impairment, prescribed treatment and treatment tolerance. Those found to be significantly correlated with adequate BP control were the female gender (OR: $1.200 ; 95 \%$ CI $[1.122 ; 1.284]$ ) and the absence of type 2 diabetes (OR: $1.120 ; 95 \%$ CI [1.025; 1.224]), absence of left ventricular hypertrophy (OR: 1.235; $95 \%$ CI $[1.133 ; 1.346])$ and absence of renal failure (OR: $1.257 ; 95 \%$ CI $[1.072 ; 1.473])$. It was also observed that patients receiving a fixed-dose bitherapy or a fixed-dose bitherapy in addition to another monotherapy were more likely to have their BP reduced than patients receiving more than 3 treatments (respectively OR: 1.234; 95\% CI [1.089; 1.397] and OR: $1.196 ; 95 \%$ CI [1.050; 1.362]).

\section{Treatment tolerance}

Overall, the study treatment was well tolerated. Only $2.3 \%$ of the included patients $(\mathrm{n}=564)$ presented with a serious medical event. Main events reported among these patients were a necessity for hospitalization $(0.7 \%$ in Group A, $0.9 \%$ in Group B, and $0.9 \%$ in Group C), and a cardiovascular event $(0.4 \%$ in Group A, $0.7 \%$ in
Group B, and $0.9 \%$ in Group C). At the end of follow-up, the vast majority of patients $(81.8 \%)$ continued treatment with the low-dose perindopril/indapamide combination ( $2 \mathrm{mg} / 0.625 \mathrm{mg}$ ). In $11 \%$ of patients, the doses had to be increased to $4 \mathrm{mg} / 1.250 \mathrm{mg}$; the perindopril/indapamide combination was replaced by another treatment in 5.1\% of patients and discontinued in $2.1 \%$ of patients.

\section{Discussion}

The findings of the present observational study carried out with a very large sample of patients provide information on an aspect that has never been studied in hypertension: the potential influence of MS on the treatment action in terms of BP lowering. The most important result is that the presence of a pre-existing MS does not influence the antihypertensive effect of the treatment since BP was lowered to the same extent in both subgroups of patients without MS and patients with MS, whatever the number of factors that constitute the syndrome. Given either as initiation in untreated hypertensive patients, or as replacement or adjunctive therapy in those patients already treated but insufficiently controlled or experiencing adverse effects of their antihypertensive treatment, the fixed low-dose antihypertensive combination used in this study achieved significant BP reduction from baseline, and optimal BP control in $64 \%-70 \%$ of the patients. 
Our results may not be discussed by comparing with other studies since none has studied the factors that may predict the BP response after treatment in hypertensive patients with MS and very few have specifically compared BP lowering between patients without MS and patients with MS - at least three of the five determining traits. Reported results differ widely and there is a need for further research. A Spanish study has analyzed a large subset of patients ( $n=6736$ ) with MS defined according to the NCEP-ATPIII criteria; unlike our findings, its results show that although hypertensive patients with MS were receiving more antihypertensive medication than those without, the rate of BP control was lower in patients with MS (Barrios et al 2007). Despite the fact that further research is needed to confirm the independence of the antihypertensive effect of the treatment therapy in hypertensive patients with MS, and to determine whether all medications used in hypertension display similar independence, our findings are promising and show that a low-dose combination therapy given as recommended by the international guidelines may, in about $65 \%-70 \%$ of hypertensive patients with MS, control high blood pressure, one of the most frequently encountered components of MS (Hu et al 2004).

Our results show, in particular, significant effects of the study treatment on systolic BP lowering, whatever the treatment status: initiation, switch, or adjunctive therapy, and independently from the presence or not of MS. This effect may be related to the specific vascular effect of the combination perindopril/indapamide on large arteries and microcirculation: this combined therapy was shown to restore both capillary density and large arterial compliance in hypertensive patients (Asmar et al 2001; Levy et al 2001).

This vascular effect is likely to provide, in turn, a more selective SBP reduction and an improvement in coronary blood flow reserve (Mourad et al 2003; London et al 2004), two properties that contribute to a better target organ protection. As a matter of fact, the perindopril/indapamide combination has recently demonstrated in the ADVANCE trial, the largest trial ever carried out among diabetic patients, its ability to reduce cardiovascular and total mortality, as well as cardiovascular and renal complications (ADVANCE 2007).

This study displays also a body of epidemiologic characteristics regarding that population of hypertensive patients who have also MS. The syndrome was screened among the study population using the NCEP-ATPIII criteria which are considered the simplest and the most commonly applied for MS detection (Mulè et al 2006). The incidence rate of MS among the hypertensive patients of our study is somewhat comparable to that found in other studies - although the criteria utilized to detect MS were not always those of the NCEP-ATPIII: about one third (Mulè et al 2005; Tamaki et al 2006; Ferrara et al 2007a, b). Some discrepancies may be noticed, however, with lower reported rates (Leoncini et al 2005, 2007), higher (Garcia-Puig et al 2006; Mulè et al 2007), and even far more elevated rates (Kelishadi et al 2005).

Among the reported hypertension-related cofactors of cardiovascular risk in patients with MS, the identification of high rates of physical inactivity (81\%) and tobacco consumption ( $28 \%$ of the patients), significantly higher than in patients without MS, suggest that much effort should be made for patient's education since these two factors are the only ones that may be modified by lifestyle changes. The other cardiovascular risk factors identified that were all significantly more frequent among MS patients than among MS-free patients confirm that in hypertensive patients with MS, the cardiovascular risk is significantly raised. The prognostic value of MS among hypertensive populations has been studied in many studies (Schillaci et al 2004; Leoncini et al 2005; Mulè et al 2005, 2006, 2007; Cuspidi et al 2007; Ferrara et al 2007a, b; Navarro et al 2007) that found a significantly increased occurrence of cardiovascular complications and events in hypertensive patients with MS.

The results of the present study indicate a real need for metabolic screening in all hypertensive patients, and emphasize the importance of prevention in the management of hypertension which should focus on both BP lowering and correcting associated risk factors. MS associated with hypertension promotes organ damage and may, at least partly, explain the high cardiovascular morbidity and mortality that is observed in hypertensive patients with MS. Controlling high BP should help in reducing this risk. This study shows that BP may be controlled in hypertensive patients with MS and that the presence of MS does not affect the action of the fixed dose perindopril/indapamide combination which is well known for its cardiovascular protective effect in diabetic patients and given in compliance with the guidelines, whether as initiation, replacement, or as adjunctive therapy.

\section{References}

ADVANCE Collaborative Group. 2007. Effects of a fixed combination of perindopril and indapamide on macrovascular and microvascular outcomes in patients with type 2 diabetes mellitus (the ADVANCE trial): a randomised controlled trial. Lancet, 370:829-40.

Ajjan R, Carter AM, Somani R, et al. 2007. Ethnic differences in cardiovascular risk factors in healthy Caucasian and South Asian individuals with the metabolic syndrome. J Thromb Haemost, 754-60. 
Alberti KG, Zimmet P, Shaw J. 2005. Metabolic syndrome - a new worldwide definition. Lancet, 366:1059-62.

Alberti KG, Zimmet P. 1998. Definition, diagnosis and classification of diabetes and its complications. Part I: diagnosis and classification of diabetes provisional report of a WHO consultation. Diabet Med, 15:539-53.

Asmar RG, London GM, O'Rourke ME, et al. 2001. Improvement in blood pressure, arterial stiffness and wave reflections with a very-low-dose perindopril/indapamide combination in hypertensive patients: a comparison with atenolol. Hypertension, 38:922-6.

Balkau B, Charles MA. 1999. Comments on the provisional report from the WHO consultation. European Group for the Study of Insulin Resistance. Diabet Med, 16:442-3.

Barrios V, Escobar C, Calderon A, et al. 2007. Adequacy of the treatment of hypertensive patients with metabolic syndrome. Med Clin (Barc), 128:647-51.

Borch-Johnsen K. 2007. The metabolic syndrome in a global perspective. The public health impact -secondary publication. Dan Med Bull, 54:157-9.

Choi KM, Kim SM, Kim YE, et al. 2007. International Diabetes federation. Prevalence and cardiovascular disease risk of the metabolic syndrome using National Cholesterol Education program and International Diabetes Federation definitions in the Korean population. Metabolism, 56:552-8.

Cuspidi C, Meani S, Valerio C, et al. 2007. Age and target organ damage in essentialhypertension: role of the metabolic syndrome. Am J Hypertens, 20:296-303.

Day C. 2007. Metabolic syndrome, or What you will: definition and epidemiology. Diab Vasc Dis Res, 4:32-8.

De Jongh RT, Serné EH, Ijzerman RG. 2004. Impaired microvascular function in obesity. Implications for obesity associated microangiopathy, hypertension and insulin resistance. Circulation, 109:2529-35.

ESC-ESH. 2007. Guidelines for the Management of Arterial Hypertension. 2007. The Task Force for the Management of Arterial Hypertension of the European Society of Hypertension (ESH) and the European Society of Cardiology (ESC). J Hypertens, 25:1105-87.

Expert Panel on Detection, Evaluation, and Treatment of High Blood Cholesterol in Adults. 2001. Executive summary of the third report of the National Cholesterol Education Program (NCEP) expert panel on detection, evaluation, and treatment of high blood cholesterol in adults (Adult Treatment Panel III). JAMA, 285:2486-97.

Ferrara LA, Cardoni O, Mancini M, et al. 2007b. Metabolic syndrome and left ventricular hypertrophy in a general population. Results from the Gubbio Study. J Hum Hypertens, 21:795-801.

Ferrara LA, Guida L, Ferrara F, et al. 2007a. Cardiac structure and function and arterial circulation in hypertensive patients with and without metabolic syndrome. J Hum Hypertens, 21:729-35.

Ford ES, Giles WH, Dietz WH. 2002. Prevalence of the metabolic syndrome among US adults: findings from the Third National Health and Nutrition Examination Survey. JAMA, 287:356-9.

Garcia-Puig J, Ruilope LM, Luque M, et al. 2006. AVANT Study Group Investigators. Glucose metabolism in patients with essential hypertension. Am J Med, 119:318-26.

Grundy SM, Brewer HB, Cleeman JL, et al. 2004. Definition of Metabolic Syndrome: Report of the National Heart, Lung, and Blood Institute/ AHA conference on scientific issues related to definitions. Circulation, 109:433-8.

Grundy SM, Cleeman JI, Daniels SR, et al. 2005. Diagnosis and management of the metabolic syndrome: an American Heart Association/National Heart, Lung, and Blood Institute Scientific Statement. Circulation, 112:2735-52.

Hu G, for the DECODE study. 2004. Prevalence of the metabolic syndrome and its relation to all-cause and cardiovascular mortality in nondiabetic European men and women. Arch Intern Med, 164:1066-76.

Julius S, Gudbrandsson T, Jamerson K, et al. 1991. The hemodynamic link between insulin resistance and hypertension. J Hypertens, 9:983-6.
Kelishadi R, Derakhstan R, Sabet B, et al. 2005. The metabolic syndrome in hypertensive and normotensive subjects: the Isfahan Healthy Heart Programme. Ann Acad Med Singapore, 34:243-9.

Kelishadi R. 2007. Childhood overweight, obesity, and the metabolic syndrome in developing countries. Epidemiol Rev, 29:62-76.

Lakka HM, Laaksonnen DE, Lakka TA, et al. 2002. The metabolic syndrome and total and cardiovascular disease mortality in middle-aged men. JAMA, 288:2709-16.

Leoncini G, Ratto E, Viazzi F, et al. 2005. Metabolic syndrome is associated with early signs of organ damage in nondiabetic hypertensive patients. J Intern Med, 257:454-60.

Leoncini G, Ratto E, Viazzi F, et al. 2007. Metabolic syndrome and ambulatory arterial stiffness index in non-diabetic patients with primary hypertension. J Hum Hypertens, 21:802-7.

Levy BI, Duriez M, Samuel JL, et al. 2001. Coronary microvasculature alteration in hypertensive rats. Effect of treatment with a diuretic and an ACE inhibitor. Am J Hypertens, 14:7-13.

London GM, Asmar RG, O’Rourke M, et al. 2004. Mechanism(s) of selective systolic blood pressure reduction after a low-dose combination of perindopril/indapamide in hypertensive subjects: comparison with atenolol. J Am Coll Cardiol, 43:92-9.

Mitrakou A. 2006. Women's health and the metabolic syndrome. Ann NY Acad Sci, 1092:33-48.

Mourad JJ, Hanon O, Deverre JR, et al. 2003. Improvement of impaired coronary vasodilator reserve in hypertensive patients by low-dose ACE inhibitor/diuretic therapy: a pilot PET study. J Renin Angiotens Aldoster Syst, 4:94-5.

Mulè G, Cottone S, Nardi E, et al. 2006. Metabolic syndrome in subjects with essential hypertension: relationships with subclinical cardiovascular and renal damage. Minerva Cardioangiol, 54:173-94.

Mulè G, Nardi E, Cottone S, et al. 2005. Influence of metabolic syndrome on hypertension-related target organ damage. J Intern Med, 257:503-13.

Mulè G, Nardi E, Cottone S, et al. 2007. Relationship of metabolic syndrome with pulse pressure in patients with essential hypertension. Am J Hypertens, 20:197-203.

Navarro J, Redon J, Cea-Calvo L, et al. 2007. Metabolic syndrome, organ damage and cardiovascular disease in treated hypertensive patients. The ERIC-HTA study. Blood Press, 16:20-7.

Nilsson PM, Engström G, Hedblad B. 2007. The metabolic syndrome and incidence of cardiovascular disease in non-diabetic subjects. A population-based study comparing three different definitions. Diabet Med, 24:464-72.

Qiao Q, Gao W, Zhang L, et al. 2007. Metabolic syndrome and cardiovascular disease. Ann Clin Biochem, 44:232-63.

Reaven GM. 1988. Banting lecture 1988: role of insulin resistance in human disease. Diabetes, 37:1595-607.

Rodilla E, Gonzalez C, Costa JA, et al. 2007. New definition of metabolic syndrome: does it have the same cardiovascular risk? Rev Clin Esp, 207:69-74.

Royer M, Castelo-Branco C, Blümel JE, et al. 2007. The US National Cholesterol Education programme Adult Treatment Panel III (NCEP ATP III): prevalence of the metabolic syndrome in postmenopausal Latin American women. Climateric, 10:164-70.

Schillaci G, Pirro M, Vando G. 2004. Prognostic value of the metabolic syndrome in essential hypertension. J Am Coll Cardiol, 43:1817-22.

Tamaki S, Nakamura Y, Yoshino T, et al. 2006. The association between morning hypertension and metabolic syndrome in hypertensive patients. Hypertens Res, 29:783-8.

Tonkin R. 2003. The X factor: obesity and the metabolic syndrome. The Science and Public Affairs Forum. World Health organization (1999) Report of a WHO consultation: definition of metabolic syndrome in definition, diagnosis, and classification of diabetes mellitus and its complications. I. Diagnosis and classification of diabetes mellitus. Geneva: World Health Organization, Department of Noncommunicable Disease Surveillance. 
